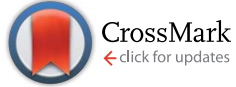

Cite this: Chem. Sci., 2015, 6, 1252

Received 27th August 2014

Accepted 14th November 2014

DOI: $10.1039 / \mathrm{c} 4 \mathrm{sc} 02612 \mathrm{~h}$

www.rsc.org/chemicalscience

\section{Stereoselective Lewis base catalyzed formal 1,3-dipolar cycloaddition of azomethine imines with mixed anhydrides $\uparrow$}

\author{
Lena Hesping, Anup Biswas, Constantin G. Daniliuc, Christian Mück-Lichtenfeld* \\ and Armido Studer*
}

Stereoselective synthesis of pyrazolidinones via dipolar cycloaddition of azomethine imines with active esters under Lewis base catalysis is presented. The active esters are readily generated in situ from the corresponding acids. Products, which are obtained with excellent diastereocontrol and high enantioselectivity, contain along with the pyrazolidinone core also the tetrahydroisoquinoline structural motif. Theoretical studies give insight into the mechanism of the formal cycloaddition reaction.

\section{Introduction}

Many natural products with interesting biological activity are based on the C1-substituted tetrahydroisoquinoline core $1 .^{\mathbf{1}}$ It is obvious that many synthetic methods have been developed for the stereoselective construction of this important core structure. ${ }^{2}$ Pyrazolidinones 2 are also interesting compounds which have found wide applications in different fields. This structural motif can be found in dyes, in pharmaceuticals and agriculturally relevant compounds. ${ }^{3}$ Pyrazolidinones of type 3 combine the structural features of both $\mathbf{1}$ and 2 and should therefore be valuable compounds which have so far not been intensively investigated (Fig. 1). ${ }^{4}$ Herein we present a novel straightforward method for the stereoselective synthesis of compounds of type 3 via 1,3-dipolar cycloaddition of azomethine imines with mixed anhydrides.

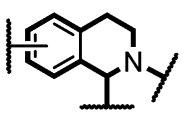

1, C1-substituted tetrahydroisoquinolines

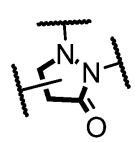

2, pyrazolidinones
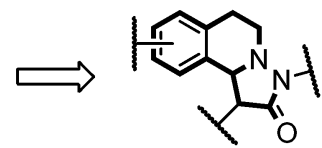

3, pyrazolidinones containing the tetrahydroisoquinoline core structure
Fig. 1 Compounds 3 combining structural features of both 1 and 2 .

Organisch-Chemisches Institut, Westfälische Wilhelms-Universität Münster Corrensstrasse 40, 48149 Münster, Germany. E-mail: studer@uni-muenster.de; Web: http://www.uni-muenster.de/Chemie.oc/studer/; Fax: +49-251-83-36523; Tel: +49251-83-33291

$\dagger$ Electronic supplementary information (ESI) available: Detailed experimental procedures, and spectral data for all compounds, including scanned images of ${ }^{1} \mathrm{H}$ and ${ }^{13} \mathrm{C}$ NMR spectra. CCDC 1019046 . For ESI and crystallographic data in CIF or other electronic format see DOI: $10.1039 / \mathrm{c} 4 \mathrm{sc} 02612 \mathrm{~h}$

\section{Results and discussion}

\section{Experimental studies}

The intermolecular $[2+3]$ cycloaddition of azomethine imines with alkynes is known for more than 45 years, ${ }^{5}$ and an enantioselective version was developed by $\mathrm{Fu}$ et al. using Cu-catalysis. ${ }^{6}$ Chen, ${ }^{7}$ Sibi, ${ }^{8 a}$ Maruoka ${ }^{9}$ and others ${ }^{8 b-\boldsymbol{d}}$ disclosed enantioselective cycloadditions of azomethine imines with electron-poor alkenes and the corresponding enantioselective dipolar cycloaddition with electron-rich alkenes was reported by Leighton ${ }^{\mathbf{1 0}}$ and Maruoka. ${ }^{11}$ Very recently, Wang et al. published amine-catalyzed enantioselective 1,3-dipolar cycloadditions of aldehydes to $C, N$ cyclic azomethine imines, where intermediately generated electron-rich enamines are the actual dipolarophiles. ${ }^{12}$

As a continuation of our studies on oxidative carbene catalysis, ${ }^{13}$ we decided to investigate the reaction of aliphatic aldehydes with azomethine imines in the presence of a $\mathrm{N}$-heterocyclic carbene (NHC) under oxidative conditions as a novel method for the preparation of compounds of type 3 . Disappointingly, we found that the azomethine imine 1a reacted with phenylacetaldehyde in the presence of triazole precatalyst and DBU under oxidative conditions to cycloadduct 4 (ref. 14) (Fig. 2). The targeted pyrazolidinone 3aa was not identified.

The reaction of phenylacetaldehyde with the NHC, oxidation to the acylazolium ion and subsequent enolization ${ }^{\mathbf{1 5}}$ to give an enolate of type $\mathbf{A}$ is obviously slower than direct reaction of phenylacetaldehyde with 1a under the applied basic conditions. We therefore switched to enolates of type $\mathbf{B}$ as potential dipolarophiles for the $[2+3]$ cycloaddition with 1a. It is important to note that stereoselective reactions with enolates formally deriving from acylammonium or acylpyridinium ions have been intensively studied in asymmetric catalysis. ${ }^{16}$ However, the application of such enolates as dipolarophiles in the reaction with azomethine imines is unknown. 

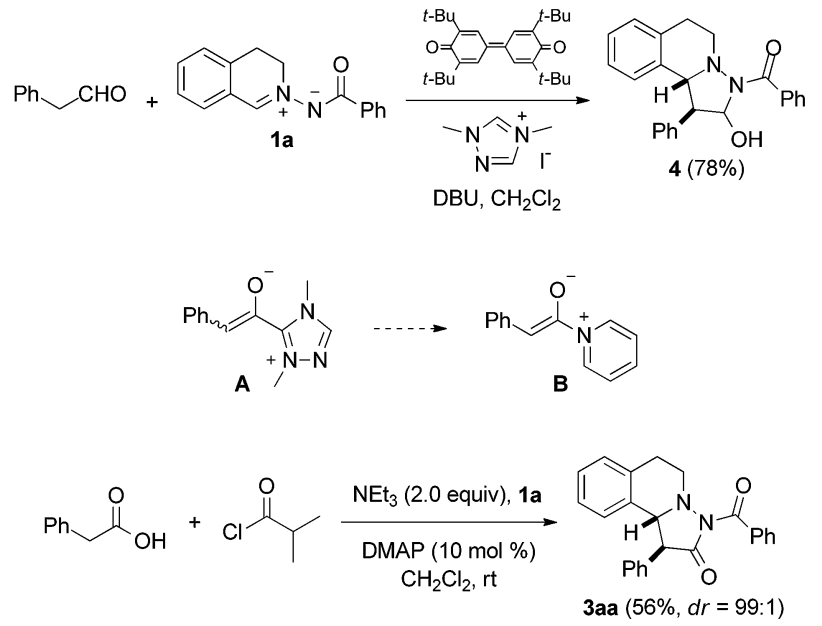

Fig. 2 Transformation of $1 \mathrm{a}$ to either 4 or $3 a a$ under different conditions.

Pleasingly, the mixed anhydride in situ generated from phenylacetic acid and isobutyric acid chloride in the presence of $\mathrm{NEt}_{3}$ reacted with 1a and DMAP (10 mol\%) to pyrazolidinone 3aa which was isolated in 56\% yield as a $99: 1$ mixture of diastereoisomers, as analyzed by HPLC..$^{17,18}$ Encouraged by this result, we continued the studies by testing the chiral commercially available Lewis bases $\mathbf{C},{ }^{19} \mathbf{D},{ }^{20}$ and $\mathbf{E},{ }^{20}$ which have successfully been used in asymmetric catalysis (Fig. 3). ${ }^{21,22}$

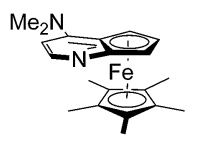

C

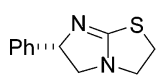

D

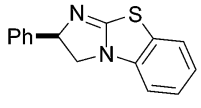

E
Fig. 3 Chiral Lewis bases C, D and E used in this study.
With catalyst C, 3aa was obtained in moderate to good yield with high diastereoselectivity $(95: 5)$ but no or very low enantioselectivity by using $i-\mathrm{Pr}_{2} \mathrm{NEt}$ or $\mathrm{Et}_{3} \mathrm{~N}$ as base (Table 1 , no. 1,2 ). Pleasingly, tetramisole D (10 mol\%) provided 3aa with significant ee $(56 \%)$ but low diastereoselectivity $(67: 33)$ which was improved to $91: 9$ upon increasing the catalyst loading to $20 \mathrm{~mol} \%$ (Table 1, no. 3, 4). Likely, back ground reaction, which is cycloaddition of the free ketene with the azomethine imine, competes at lower catalyst loading. This assumption is supported by the fact that the diastereoselectivity at lower catalyst loading was significantly lower $(67: 33$ versus $91: 9)$ and accordingly also the ee was lower. Enantioselectivity was determined by HPLC analysis (see ESI $\dagger$ ). With phenylacetyl chloride as substrate, ee and $\mathrm{dr}$ were further improved; however, yield was very low in that case (Table 1, no. 5). As compared to $\mathbf{D}$, catalyst $\mathbf{E}$ provided slightly improved selectivities (Table 1, no. 6, 7). From the experiment run with the acid chloride as a substrate it became obvious that the leaving group at the activated acid derivatives may play an important role on the selectivity. Therefore, we tested the in situ generated mixed anhydride derived from 2,4,6-trimethylbenzoyl chloride. Disappointingly, both diastereoselectivity and enantioselectivity decreased (Table 1, no. 8). However, the mixed anhydride formed from benzoyl chloride gave 3aa with excellent ee (99\%) and high diastereoselectivity (94:6) in good yield (Table 1, no. 9). We found that reaction works far more efficiently at room temperature without diminishing selectivity to a large extent and pyrazolidinone 3aa was obtained in $95 \%$ yield, $94: 6$ diastereoselectivity with $98 \%$ ee (Table 1, no. 10). The absolute and relative configuration of 3aa were unambiguously assigned by X-ray analysis (Fig. 4).

With optimized conditions in hand, we tested scope and limitation of the stereoselective cycloaddition by varying the acid component and also the azomethine imine (Fig. 5 and 6). All azomethine imines used in this study were prepared

Table 1 Reaction optimization

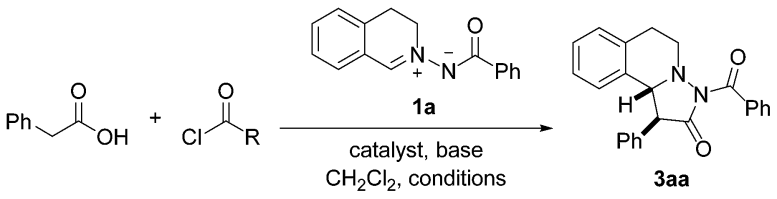

\begin{tabular}{|c|c|c|c|c|c|c|c|}
\hline No. & $\mathrm{R}$ & Cat. (mol\%) & Base & Temp $\left({ }^{\circ} \mathrm{C}\right) /$ Time $(\mathrm{h})$ & $\mathrm{dr}$ & ee $(\%)$ & Yield (\%) \\
\hline 1 & $i-\operatorname{Pr}$ & C (10) & $\mathrm{Et}_{3} \mathrm{~N}^{a}$ & $\mathrm{rt} / 16$ & $95: 5$ & 6 & 46 \\
\hline 2 & $i-\operatorname{Pr}$ & C (10) & $i-\operatorname{Pr}_{2} \mathrm{NEt}^{a}$ & $\mathrm{rt} / 14$ & $95: 5$ & $r a c$ & 71 \\
\hline 4 & $i-\operatorname{Pr}$ & $\mathbf{D}(20)$ & $i-\mathrm{Pr}_{2} \mathrm{NEt}^{a}$ & $0 / 23$ & $91: 9$ & $76^{c}$ & 74 \\
\hline 5 & $-^{d}$ & D (10) & $i-\operatorname{Pr}_{2} \mathrm{NEt}^{b}$ & $0 / 24$ & $99: 1$ & $92^{c}$ & 12 \\
\hline 6 & $i-\operatorname{Pr}$ & $\mathbf{E}(10)$ & $i-\mathrm{Pr}_{2} \mathrm{NEt}^{a}$ & $0 / 43$ & $95: 5$ & 64 & 64 \\
\hline 9 & $\mathrm{Ph}$ & $\mathbf{E}(10)$ & $i-\mathrm{Pr}_{2} \mathrm{NEt}^{b}$ & $5 / 24$ & $94: 6$ & 99 & 68 \\
\hline 10 & $\mathrm{Ph}$ & $\mathbf{E}(10)$ & $i-\mathrm{Pr}_{2} \mathrm{NEt}^{b}$ & $\mathrm{rt} / 16$ & $94: 6$ & 98 & 95 \\
\hline
\end{tabular}

${ }^{a}$ With 2.1 equiv. base. ${ }^{b}$ With 1.1 equiv. base. ${ }^{c}$ Other enantiomer formed as major isomer. ${ }^{d}$ Phenylacetyl chloride used as substrate. 


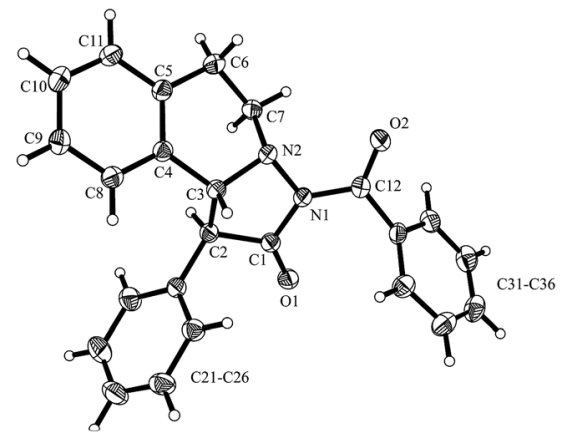

Fig. 4 X-ray structure of pyrazolidinone 3aa. Thermal ellipsoids are shown with $30 \%$ probability.
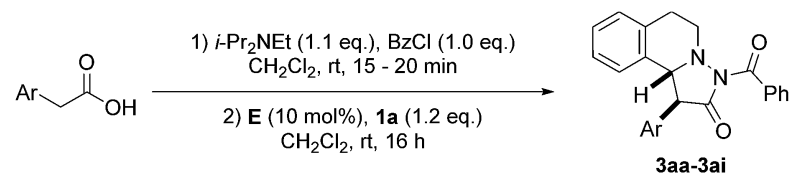
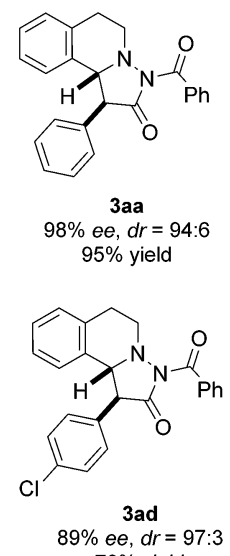

$70 \%$ yield

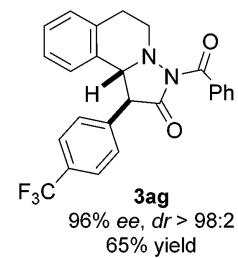

Fig. 5 Variation of the acetic acid component.

according to literature procedures (see ESI $\dagger$ ). Phenylacetic acids with both electron-donating and electron-withdrawing groups were tolerated to afford cycloaddition products 3ac-3ag in good to high yields and high enantio- and diastereoselectivity. Furthermore, the sterically demanding $o$-tolylacetic acid could be utilized furnishing 3ab with high ee and dr. Excellent selectivity and good yield were achieved with 2-naphthylacetic acid as the substrate (product 3ah, $>99 \%$ ee, $\mathrm{dr}=98: 2,82 \%$ yield). Additionally, the heteroaromatic substrate thiopheneacetic acid worked well providing cycloadduct 3ai in good yield and excellent diastereoselectivity, albeit with slightly lower ee.
Next, differently substituted azomethine imines were tested in the reaction with various acetic acid derivatives (Fig. 6). Good to high yields were obtained by using 7-bromo and 7-methoxysubstituted azomethine imines 1d and 1e (see 3da-3eh). The electron-rich azomethine imine 1d provided significantly higher ee as compared to the ee obtained with the Br-derivative 1e. Along these lines, 5-methyl-substituted azomethine imine 1b afforded pyrazolidinones $3 \mathbf{b a}$ and $\mathbf{3 b h}$ in high selectivities and good to excellent yields. Moreover, the sterically hindered 8methyl-substituted azomethine imine 1c was a good substrate and cycloadducts $3 \mathbf{c a}$ and $\mathbf{3 c h}$ were obtained in good to excellent selectivities with good yields.

All attempts to conduct the cycloaddition of the chiral ammonium enolate derived from phenylacetic acid with in situ generated $C, N$-cyclic azomethine imines according to the elegant work of Maruoka et al. ${ }^{9}$ failed. Moreover, the $N, N$-cyclic azomethine imine 2-benzylidene-5-oxopyrazolidin-2-ium-1-ide, often used in dipolar cycloaddtions, ${ }^{6-8}$ did not react with the in situ generated ammonium enolate under the tested conditions.

To show the value of pyrazolidinones as building blocks in synthesis, we tested a first follow-up reaction. To this end,
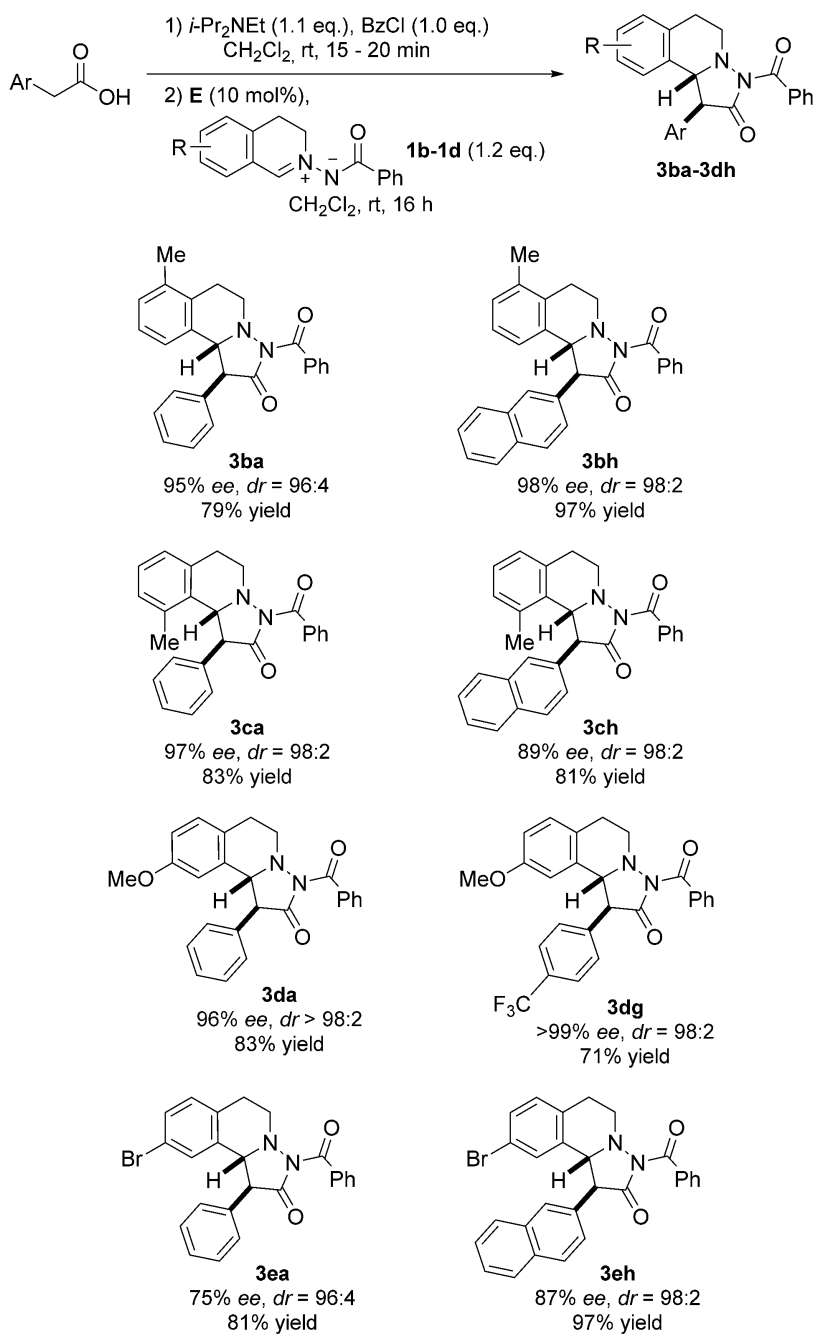

Fig. 6 Variation of the azomethine imine and the acetic acid component. 


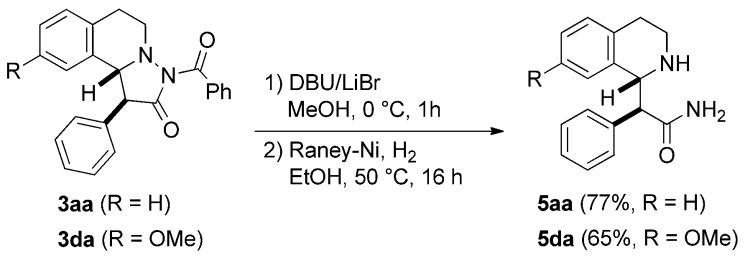

Fig. 7 Reductive cleavage of the $N-N$ bond for preparation of $\beta$ amino acid derivatives.

$N$-benzoyl deprotection in pyrazolidinones 3aa and 3da was achieved with $\mathrm{DBU} / \mathrm{LiBr}^{23}$ in $\mathrm{MeOH}$ to give the corresponding $\mathrm{NH}$-pyrazolidinones. $\mathrm{N}-\mathrm{N}$ bond cleavage by reduction with Raney-Ni/ $\mathrm{H}_{2}$ eventually provided stereospecifically the tetrahydroisoquinolines $\mathbf{5 a a}$ and $\mathbf{5 d a}$ in good yields (Fig. 7). These $\beta$-amino acid derivatives might be valuable for preparation of $\beta$-peptides. ${ }^{24}$

\section{Theoretical studies of the mechanism}

In our DFT study of the mechanism of the cycloaddition reaction, we used TPSS-D3/def2-TZVP and an implicit solvation model (COSMO), for details, see ESI. $\dagger$ We chose the reaction of intermediate $\mathbf{F}$ deriving from phenylacetic acid and catalyst $\mathbf{E}$ with azomethine imine $\mathbf{1 a}$ as our model system. The free energies, including solvation energies in $\mathrm{CH}_{2} \mathrm{Cl}_{2}$ and thermodynamic corrections at $298 \mathrm{~K}$ starting from the enolate $\mathbf{F}$ and $\mathbf{1 a}$ are given in Fig. 8.

We were not able to locate a transition structure of synchronous formation of both bonds ( $\mathrm{C}-\mathrm{C}$ and $\mathrm{C}-\mathrm{N})$ of the product (3aa). The mechanism proceeds stepwise with $\mathrm{C}-\mathrm{C}$ bond formation as the first step (TS-1), leading to an intermediate (IN-1), which subsequently forms the second $\mathbf{C}-\mathbf{N}$ bond with a very low barrier. Thus, the first step is
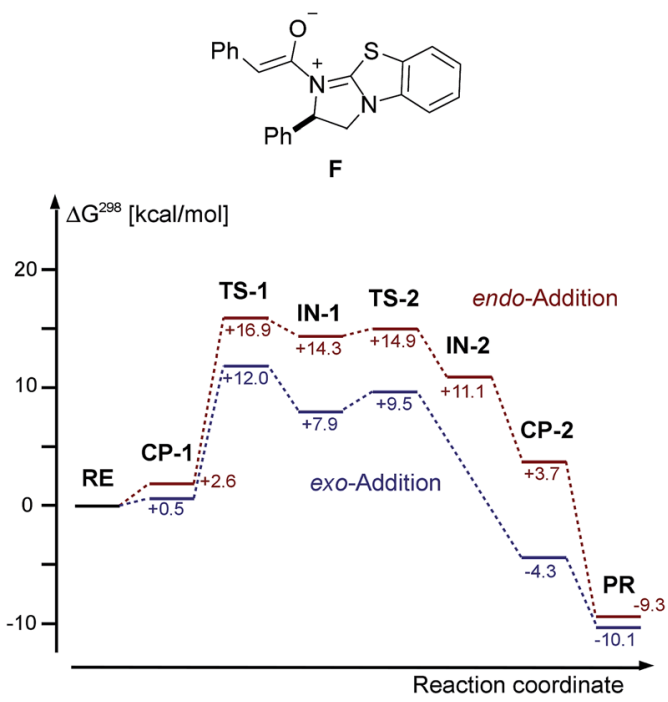

Fig. 8 Chemical structure of enolate $\mathrm{F}$ and DFT calculated (TPSS-D3/ def2-TZVP + COSMO $\left(\mathrm{CH}_{2} \mathrm{Cl}_{2}\right)$ free energies of the cycloaddition of $\mathrm{F}$ and $1 \mathrm{a} . \mathrm{RE}=1 \mathrm{a} / \mathrm{F}, \mathrm{PR}=3 \mathrm{a} a / \mathrm{E}$.

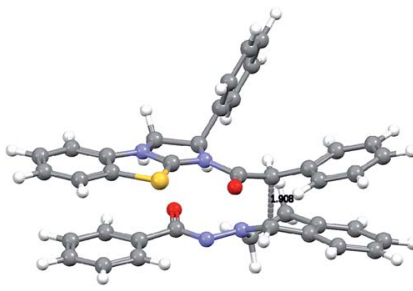

exo-TS-1

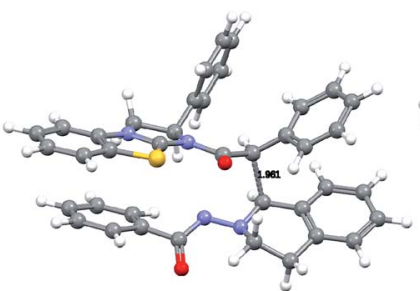

endo-TS-1

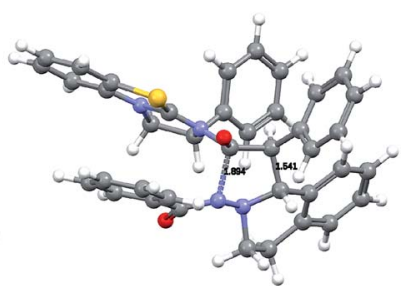

exo-TS-2

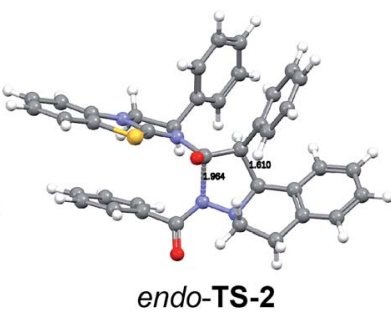

Fig. 9 DFT calculated transition structures in the cycloaddition of $F$ and $1 \mathrm{a}$.

determining the rate and the stereochemical outcome of the process. The preferred orientation of the two reactants in the pre-reactive complex CP-1 and for TS-1 is exo (see Fig. 9), in accordance with the observed diastereoselectivity of the reaction. Moreover, the absolute stereochemistry obtained in the calculations agreed with the stereochemistry observed in the experiment. In the exo reaction, we could not identify a tetrahedral intermediate $\mathbf{I N - 2}$ as for endo, the catalyst $\mathbf{E}$ is released instantaneously upon formation of the $\mathrm{C}-\mathrm{N}$ bond of 3aa. The breakup of the product complex CP-2 releases product 3aa, of which the trans-diastereoisomer is also thermodynamically the more stable one.

\section{Conclusion}

In summary, the chiral Lewis base benzotetramisole (E) catalyzes the highly enantio- and diastereoselective formation of complex pyrazilidinones with a tetrahydroisoquinoline core by 1,3-dipolar cycloaddition of $C, N$-cyclic azomethine imines and activated arylacetic acid derivatives. Reactions proceed in high yields with good to excellent diastereo- and enantioselectivity. Reductive $\mathrm{N}-\mathrm{N}$ bond cleavage and imide hydrolysis provide $\beta$-aminoamides. DFT studies reveal a stepwise mechanism with the formation of the $\mathrm{C}-\mathrm{C}$ bond as the first step which determines the rate and stereochemical outcome of the formal dipolar cycloaddition. The following $\mathrm{C}-\mathrm{N}$ bond formation occurs with a low barrier.

\section{Acknowledgements}

We thank the University of Münster and the Deutsche Forschungsgemeinschaft (DFG) within the SFB 858 (project Z1) for supporting our research. We also thank Ulrich Schreiber for the preparation of some cycloadducts. 


\section{Notes and references}

1 (a) G. J. Aune, T. Furuta and Y. Pommier, Anti-Cancer Drugs, 2002, 13, 545-555; (b) J. D. Scott and R. M. Williams, Chem. Rev., 2002, 102, 1669-1730; (c) D. Mujahidin and S. Doye, Eur. J. Org. Chem., 2005, 2005, 2689-2693; (d) K. W. Bentley, Nat. Prod. Rep., 2006, 23, 444-463; (e) F. Werner, N. Blank and T. Opatz, Eur. J. Org. Chem., 2007, 2007, 3911-3915; (f) R. J. Reddy, N. Kawai and J. i. Uenishi, J. Org. Chem., 2012, 77, 11101-11108.

2 (a) I. M. P. Huber and D. Seebach, Helv. Chim. Acta, 1987, 70, 1944-1954; (b) N. Uematsu, A. Fujii, S. Hashiguchi, T. Ikariya and R. Noyori, J. Am. Chem. Soc., 1996, 118, 4916-4917; (c) D. L. Comins, P. M. Thakker, M. F. Baevsky and M. M. Badawi, Tetrahedron, 1997, 53, 16327-16340; (d) M. Chrzanowska and M. D. Rozwadowska, Chem. Rev., 2004, 104, 3341-3370; (e) Z. Li and C.-J. Li, Org. Lett., 2004, 6, 4997-4999; (f) M. S. Taylor, N. Tokunaga and E. N. Jacobsen, Angew. Chem., 2005, 117, 6858-6862; $(g)$ N. Sasamoto, C. Dubs, Y. Hamashima and M. Sodeoka, J. Am. Chem. Soc., 2006, 128, 14010-14011; $(h)$ K. Umetsu and N. Asao, Tetrahedron Lett., 2008, 49, 2722-2725; (i) M. Chang, W. Li and X. Zhang, Angew. Chem., Int. Ed., 2011, 50, 10679-10681.

3 (a) G. J. Blackwell and R. J. Flower, Br. J. Pharmacol., 1978, 63, 360P; (b) H. L. White, J. L. Howard, B. R. Cooper, F. E. Soroko, J. D. McDermed, K. J. Ingold and R. A. Maxwell, J. Neurochem., 1982, 39, 271-273; (c) L. N. Jungheim, S. K. Sigmund and J. W. Fisher, Tetrahedron Lett., 1987, 28, 285-288; (d) J. M. Indelicato and C. E. Pasini, J. Med. Chem., 1988, 31, 1227-1230; (e) C. Turk, J. Svete, B. Stanovnik, L. Golič, S. Golič-Grdadolnik, A. Golobič and L. Selič, Helv. Chim. Acta, 2001, 84, 146-156; $(f)$ K. Yoshimura, T. Oishi, K. Yamaguchi and N. Mizuno, Chem.-Eur. J., 2011, 17, 3827-3831.

4 (a) R. Huisgen, R. Grashey, Germany Pat., DE1203793, 1965; (b) S. Andreae, E. Schmitz, H. Sonnenschein, G. Dörnyei, C. Szántay and J. Tamás, J. Prakt. Chem., 1985, 327, 445-454. 5 H. Dorn and A. Otto, Chem. Ber., 1968, 101, 3287-3301.

6 R. Shintani and G. C. Fu, J. Am. Chem. Soc., 2003, 125, 1077810779.

7 W. Chen, X.-H. Yuan, R. Li, W. Du, Y. Wu, L.-S. Ding and Y.-C. Chen, Adv. Synth. Catal., 2006, 348, 18181822.

8 (a) M. P. Sibi, D. Rane, L. M. Stanley and T. Soeta, Org. Lett., 2008, 10, 2971-2974; (b) H. Suga, A. Funyu and A. Kakehi, Org. Lett., 2007, 9, 97-100; (c) W. Chen, W. Du, Y.-Z. Duan, Y. Wu, S.-Y. Yang and Y.-C. Chen, Angew. Chem., Int. Ed., 2007, 46, 7667-7670; (d) K. Tanaka, T. Kato, Y. Ukaji and K. Inomata, Heterocycles, 2010, 80, 887-893.

9 T. Hashimoto, Y. Maeda, M. Omote, H. Nakatsu and K. Maruoka, J. Am. Chem. Soc., 2010, 132, 4076-4077.

10 S. Shirakawa, P. J. Lombardi and J. L. Leighton, J. Am. Chem. Soc., 2005, 127, 9974-9975.

11 T. Hashimoto, M. Omote and K. Maruoka, Angew. Chem., Int. Ed., 2011, 50, 3489-3492.
12 W. Li, Q. Jia, Z. Du, K. Zhang and J. Wang, Chem.-Eur. J., 2014, 20, 4559-4562.

13 Reviews: (a) C. E. I. Knappke, A. Imami and A. J. Von Wangelin, ChemCatChem, 2012, 4, 937-941; (b) S. De Sarkar, A. Biswas, R. C. Samanta and A. Studer, Chem.-Eur. J., 2013, 19, 4664-4678.

14 Compound 4 was formed as a single diastereoisomer. The relative configuration at the acetal stereocenter could not be unambiguously assigned. The relative configuration of the other two stereocenters could be assigned as trans by oxidation of $\mathbf{4}$ to 3aa. The structure of 3aa was assigned by $\mathrm{X}$-ray analysis, see below.

15 (a) M. Wang, Z. Huang, J. Xu and Y. R. Chi, J. Am. Chem. Soc., 2014, 136, 1214-1217, See also ; (b) X. Zhao, K. E. Ruhl and T. Rovis, Angew. Chem., Int. Ed., 2012, 51, 12330-12333; (c) J. Mo, R. Yang, X. Chen, B. Tiwari and Y. R. Chi, Org. Lett., 2013, 15, 50-53.

16 Review on ammonium enolate chemistry, see: M. J. Gaunt and C. C. C. Johansson, Chem. Rev., 2007, 107, 5596-5605, Review on enolates derived from ketenes, see: D. H. Paull, A. Weatherwax and T. Lectka, Tetrahedron, 2009, 65, 67716803.

17 In situ generation of ammonium enolates from acid derivatives, see: $(a)$ G. S. Cortez, R. L. Tennyson and D. Romo, J. Am. Chem. Soc., 2001, 123, 7945-7946; (b) G. S. Cortez, S. H. Oh and D. Romo, Synthesis, 2001, 17311736; (c) S. H. Oh, G. S. Cortez and D. Romo, J. Org. Chem., 2005, 70, 2835-2838; (d) H. Nguyen, G. Ma, T. Gladysheva, T. Fremgen and D. Romo, J. Org. Chem., 2011, 76, 2-12 and references cited thein. From acid fluorides: E. Bappert, P. Müller and G. C. Fu, Chem. Commun., 2006, 2604-2606.

18 In situ generation of ammonium enolates and usage of catalytic amounts of a chiral Lewis base, see: (a) T. Bekele, M. H. Shah, J. Wolfer, C. J. Abraham, A. Weatherwax and T. Lectka, J. Am. Chem. Soc., 2006, 128, 1810-1811; (b) J. Wolfer, T. Bekele, C. J. Abraham, C. Dogo-Isonagie and T. Lectka, Angew. Chem., Int. Ed., 2006, 45, 7398-7400; (c) X. Xu, K. Wang and S. G. Nelson, J. Am. Chem. Soc., 2007, 129, 11690-11691; (d) L. C. Morrill and A. D. Smith, Chem. Soc. Rev., 2014, 43, 6214-6226.

19 G. C. Fu, Acc. Chem. Res., 2000, 33, 412-420.

20 (a) V. B. Birman and X. Li, Org. Lett., 2006, 8, 1351-1354. Application as catalyst for kinetic resolution of secondary alcohols, see: X. Yang, G. Lu and V. B. Birman, Org. Lett., 2010, 12, 892-895.

21 Review on Lewis base catalysis, see: S. E. Denmark and G. L. Beutner, Angew. Chem., Int. Ed., 2008, 47, 1560-1638. Review on the use of isothioureas as catalysts, see: J. E. Taylor, S. D. Bull and J. M. J. Williams, Chem. Soc. Rev., 2012, 41, 2109-2121.

22 In situ generation of ammonium enolates and usage of catalytic amounts of tetramisole type Lewis bases in C-Cbond forming reactions, see: (a) C. A. Leverett, V. C. Purohit and D. Romo, Angew. Chem., Int. Ed., 2010, 49, 9479-9483; (b) D. Belmessieri, L. C. Morrill, C. Simal, A. M. Z. Slawin and A. D. Smith, J. Am. Chem. Soc., 2011, 133, 2714-2720; (c) L. C. Morrill, T. Lebl, A. M. Z. Slawin 
and A. D. Smith, Chem. Sci., 2012, 3, 2088-2093; (d) C. Simal, T. Lebl, A. M. Z. Slawin and A. D. Smith, Angew. Chem., Int. Ed., 2012, 51, 3653-3657; (e) G. Liu, M. E. Shirley, K. N. Van, R. L. McFarlin and D. Romo, Nat. Chem., 2013, 5, 1049-1057.
23 A. Studer, T. Hintermann and D. Seebach, Helv. Chim. Acta, 1995, 78, 1185-1206.

24 (a) D. Seebach, A. K. Beck and D. J. Bierbaum, Chem. Biodiversity, 2004, 1, 1111-1239; (b) D. Seebach and G. Lelais, Biopolymers, 2004, 76, 206-243; (c) D. Seebach and J. Gardiner, Acc. Chem. Res., 2008, 4, 1366-1375. 